\title{
Radio-Opaque Filaments Guided Bile Duct Division During Living Donor Liver Transplantation, a Simple Solution to an Ongoing Dilemma
}

\author{
Ahmed M. I. Taha ${ }^{1 *}$, Ramy A. Hassan ${ }^{1}$, Magdy M. Mahdy ${ }^{2}$, Mostafa S. Abbas ${ }^{2}$, Nahed A. Makhlouf ${ }^{3}$, \\ Sayed H.A. Hassaneen ${ }^{4}$, Tameem M. F. Ibraheem ${ }^{1}$
}

${ }^{1} \mathrm{HPB}$ Surgery and Liver Transplantation Unit, Surgery Department,

Al-Rajhi University Liver Hospital, Assiut University, Egypt

${ }^{2}$ Anesthesia and Intensive Care Department, Assiut University Hospital, Assiut University, Egypt

${ }^{3}$ Tropical Medicine and Gastroenterology Department, Al-Rajhi University Liver Hospital,

Assiut University, Egypt

${ }^{4}$ Diagnostic Radiology Department, Assiut University Hospital, Assiut University, Egypt

\section{ABSTRACT}

Background: We describe our experience with two techniques of bile duct division in donors of right lobe living donor liver transplantation (RL-LDLT).

Methods: 49 RL-LDLT done in Al-Rajhi Liver Hospital, Assiut University, Egypt were divided into 2 eras; from November 2014 till September 2018, the site of biliary division in 29 donors was marked by metal clips (Clips group) and from October 2018 till September 2019, 20 donors were marked by radio-opaque filaments (ROF group).

Results: There were no differences between groups in donors' and recipients' baseline characteristics. In ROF group there were less number of bile ducts stumps (2, range 1-3 versus 2 range $1-4$ in Clips group, $p=0.044$ ), less number of "imprecise-transection" (1 $(5 \%)$ versus $11(37.9 \%)$ in Clips group, $p=0.009)$ and fewer number intraoperative cholangiographies performed (1, range 1-2 versus 2 range 1-3 in Clips group, $p=0.001$ ). There were no differences between groups in the number of biliary anastomoses or incidence of biliary complications in donors or recipients. Median follow up is 33 months (range 8-66). Conclusions: Marking biliary division by ROF is a simple and minor modification but can decrease the difficulty of surgery and reduce exposure of donor and operating team to radiation.

Key words: liver transplantation, living donor, bile duct division, biliary stricture, bile leak

\section{INTRODUCTION}

Bile duct division is considered the most critical step in adult right lobe hepatectomy for living donor liver transplantation (RL-LDLT) (1). As donor safety is of fundamental importance, bile duct division is always designed to guard against donor biliary stricture. However, as the number of bile ducts in the graft is one of the significant determinants of biliary complications in the recipient, a balance should be maintained while cutting the bile duct in the donor to have the least number of bile ducts in the graft without violating the donor safety. Many tricks and modifications have been devised in the techniques of
*Corresponding author: Ahmed M. I. Taha, MD Second floor, Surgery Department Assiut University Hospital, Assiut Egypt

Tel.:+ 201015972104

E-mail: ahmed_taha@aun.edu.eg
Received: 29.07 .2020

Accepted: 16.11 .2020 
transection in the donors to precisely determine the exact site of cutting (2). As there are still variations in the techniques, this means that there is still a room for improvements.

In this article, we describe single center experience with two techniques of bile duct division in two time periods.

\section{PATIENTS AND METHODS}

\section{Patients' selection}

Fifty-one LDLT have been done in Al-Rajhi Liver Hospital, Assiut University, a tertiary level university hospital dedicated to hepatobiliary disorders and liver transplantation in southern Egypt, in the period from November 2014 till September 2019. Two of them were left lobe donation, and were excluded from this study, and the remainder 49 patients were modified RL-LDLT (without middle hepatic vein). Ethical approval was obtained by Ethical Committee of Faculty of Medicine, Assiut University. All patients signed prospectively an informed consent that indicated that their data would be stored in an electronic database and the data would possibly be published maintaining their anonymity.

The included 49 patients were separated into 2 eras. In the first era (from November 2014 till September 2018), 29 donors were done with biliary division guided by metal clips (Clips group). While in the second era (from October 2018 till September 2019), 20 donors were done with biliary division guided by radio-opaque filaments (ROF group).

\section{Technique of bile duct division}

Initially during hilar dissection, the right hepatic artery and right portal vein were dissected free from the right hilar plate. Immediately before the start of parenchymal dissection a tape was used for liver hanging excluding the right hepatic artery and right portal vein. After completion of parenchymal transection, the hilar plate became exposed. Then one of the following two techniques was performed:

\section{Clips guided technique (Clips group)}

Two or three metal clips were applied to the edge of the exposed hilar plate at the proposed site for transection. An intraoperative cholangiogram (IOC) was done through a catheter inserted in the cystic duct. The relationship between the clips and the proposed site of transection was identified and then the division of the right hilar plate was done with fine scissors under a direct view. Division was done by cutting small snip followed by repeating $\mathrm{IOC}$ especially in donors with multiple ducts till all hilar plate was divided. Small arterial bleeders encountered after division of hilar plate were controlled with 6/0 Prolene (Ethicon, Somerville, NJ) sutures. The stump was closed by $6 / 0$ PDS II (Ethicon, Somerville, NJ) oversewing interrupted sutures. A final IOC was done to detect any leakage and to ensure the integrity of donor bile duct.

\section{Radio-opaque filaments guided technique (ROF group)}

Two pieces of a suitable length of a radio-opaque filament were extracted from a gauze and then they were stitched by two $6 / 0$ Prolene stitches perpendicular to the exposed hilar plate at the proposed site for transection as showen in fig. 1 and 2. IOC, transection and stump closure are done in the same manner as in clip guided technique.

\section{Recipient biliary reconstruction}

Biliary reconstruction in the recipients was performed by duct-to-duct anastomosis with interrupted 6/0 PDS II with the knots outside the lumen. External

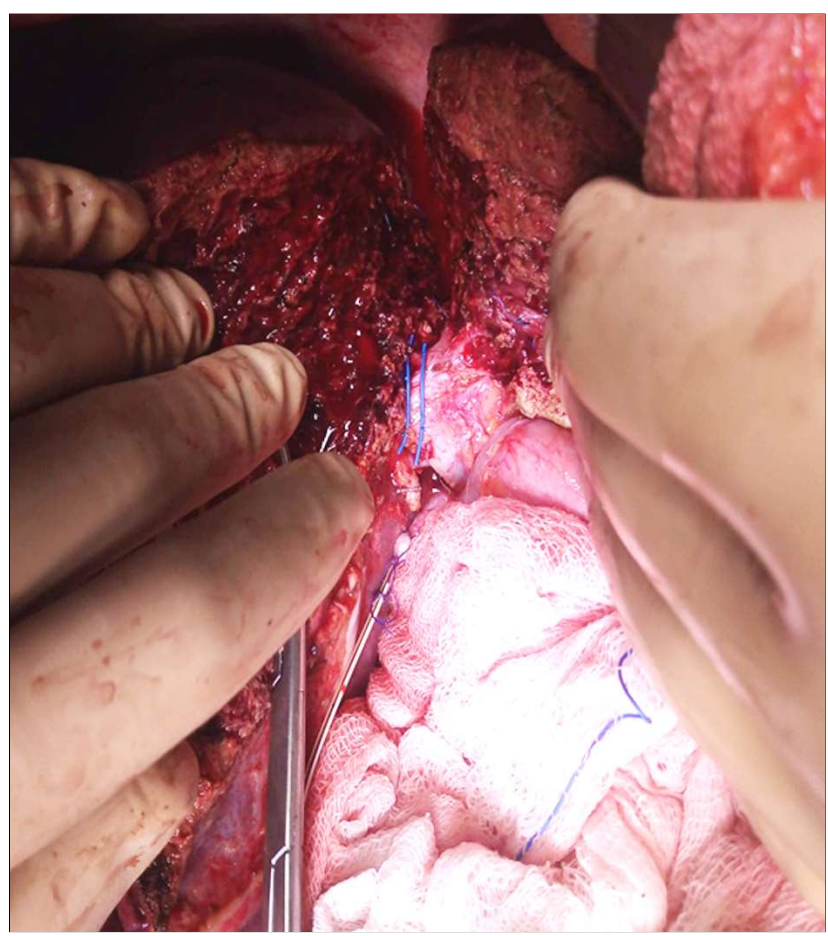

Figure 1 - An operative photos shows 2 radiopaque filaments stitched to the right hilar plate during right lobe living donor liver donation 


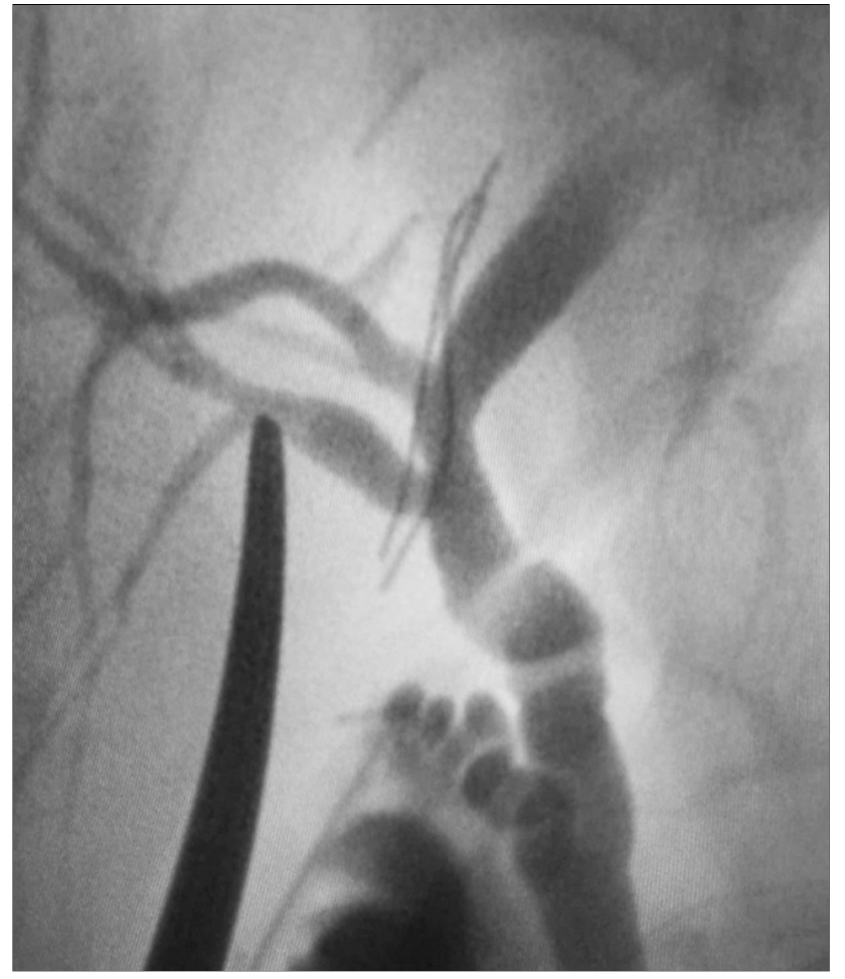

Figure 2 - An intraoperative cholangiography during the same operation in fig. 1.

biliary stents were inserted in selected patients with difficult anastomoses or small ducts. In few occasions; 2 very close ducts were converted to one duct. No hepatico-jejunostomy was done in any patient.

\section{Data collection}

Demographic, anatomical, clinical and surgical data were collected from a prospectively maintained database. Variation of the donor's biliary anatomy was reviewed based on preoperative magnetic resonance cholangiography (MRC) and compared to the IOC. Number of IOC's, number of bile duct openings in the graft, if ductoplasty was done and number of biliary anastomoses were recorded. First and final IOC's were excluded from the comparisons as they were consistent in both groups. If the number of bile ducts openings after transection turned out to be more than the estimated number of ducts in IOC, this was counted as "imprecise transection".

Postoperative complications of donors and recipients were categorized based on Clavien-Dindo classification (3). Biliary leakage was defined according to the international study group for liver surgery (ISGLS) as fluid with bilirubin level at least 3 times serum level in the abdominal drain or intra-abdominal fluid on or after post-operative day three. It is further graded into
(A) if no or minimal change in patient management occurred, (B) if leakage lasted more than a week or any intervention was required apart from laparotomy or (C) if laparotomy was required (4). Biliary stricture was defined as a segmental narrowing around the biliary anastomosis or stent was inserted by endoscopic cholangiography. All donors and recipients were being followed-up regularly in the transplant clinic (or by internet-based communication tools for 2 international patients). Donors were being followed-up for six months; afterwards their health and wellbeing were enquired about, and recorded, through the recipients as all transplants were exclusively from close relatives.

\section{Statistical analysis}

Categorical variables were presented as numbers and percentages, and continuous variables were expressed as mean and standard deviation if normally distributed (assessed by Shapiro-Wilk test) or medians and ranges if not. For the comparative analysis, differences between the 2 groups were evaluated using the Mann-Whitney $U$ test for continuous variables and the Fisher's exact test for categorical variables, respectively. A $p$-value $<0.05$ was considered statistically significant. All analyses were performed using SPSS 26 statistical package.

\section{RESULTS}

Comparison of operative data according to the method of bile duct visualization

There were no differences between groups in donor age, gender or BMI, as shown in table 1. The number of ducts detected in MRC or in IOC was not different between groups. In ROF group; median number of actual bile ducts stumps in the grafts were 2 (range 13 ), which was significantly less than that number in Clips group (2 range 1-4, $p=0.044$ ). The number of "imprecise transections" was significantly less in ROF group (1 (5\%) compared to 11 (37.9\%) in Clips group, $\mathrm{p}=0.009$ ). Fewer IOC's were done in ROF group (median 1 (range 1-2) compared to 2 (range 1-3) in Clips group, $p=0.001)$.

\section{Biliary complications in the donors}

Table 2 summarizes donors with biliary complications. A total of 4 occasions of bile leaks occurred in the Clips group, 3 were of grade A and one of grade B that required drainage under interventional radiology, compared to 2 occasions of grade A leaks in the ROF 
Table 1 - Preoperative and operative donors' characteristics

\begin{tabular}{|c|c|c|c|}
\hline Variable & $\begin{array}{c}\text { Clips group } \\
(n=29)\end{array}$ & $\begin{array}{c}\text { ROF group } \\
(n=20)\end{array}$ & $P$ value \\
\hline Age $26(18-48)$ & $23(18-41)$ & 0.371 & \\
\hline Gender $(\mathrm{m} / \mathrm{f})$ & $12 / 17(41.4 / 58.6 \%)$ & $10 / 10(50 / 50 \%)$ & 0.556 \\
\hline $\mathrm{BMI}\left(\mathrm{kg} / \mathrm{m}^{2}\right)$ & $24.8(21.2-29.2)$ & $25.2(23.5-28.9)$ & 0.416 \\
\hline $\begin{array}{c}\text { Number of ducts in MRC } \\
1 \\
2 \\
3\end{array}$ & $\begin{array}{c}2(1-2) \\
10 \\
19 \\
0\end{array}$ & $\begin{array}{c}2(1-2) \\
8 \\
12 \\
0\end{array}$ & 0.697 \\
\hline $\begin{array}{c}\text { Number of ducts in IOC } \\
1 \\
2 \\
3\end{array}$ & $\begin{array}{c}2(1-3) \\
8 \\
17 \\
4\end{array}$ & $\begin{array}{c}2(1-3) \\
7 \\
11 \\
2\end{array}$ & 0.542 \\
\hline $\begin{array}{c}\text { Number of ducts after division } \\
1 \\
2 \\
3 \\
4\end{array}$ & $\begin{array}{c}2(1-4) \\
5 \\
13 \\
10 \\
1\end{array}$ & $\begin{array}{c}2(1-3) \\
6 \\
12 \\
2 \\
0\end{array}$ & 0.044 \\
\hline Number of "imprecise transections" & $11(37.9 \%)$ & $1(5 \%)$ & 0.009 \\
\hline $\begin{array}{l}\text { Number of IOC's performed } \\
\text { (excluding first and final ones) } \\
1 \\
2 \\
3\end{array}$ & $\begin{array}{c}2(1-3) \\
7 \\
16 \\
6\end{array}$ & $\begin{array}{l}1(1-2) \\
14 \\
6 \\
0\end{array}$ & 0.001 \\
\hline
\end{tabular}

Numbers are medians (range) or numbers (percentages). BMI; Body Mass Index, MRC; magnetic resonance cholangiography, IOC; intraoperative cholangiography.

group. No biliary strictures were observed in any of the donors in either of the groups. There was no significant difference in the incidence of neither biliary complications nor non-biliary complications between the groups. Hospital stay was significantly less in the ROF group (median 7, range 5-11) compared to Clips group (median 8, range 6-16), $p=0.013$. All donors are alive and currently doing well, carrying out normal daily

Table 2 - Donors' outcomes

\begin{tabular}{|c|c|c|c|}
\hline Variable & $\begin{array}{l}\text { Clips group } \\
(\mathrm{n}=29)\end{array}$ & $\begin{array}{c}\text { ROF group } \\
(\mathrm{n}=20)\end{array}$ & P value \\
\hline \multicolumn{4}{|l|}{ Lab } \\
\hline Total bilirubin, peak (mg/dL) & $2.9 \pm 1.5$ & $2.5 \pm 0.8$ & 0.218 \\
\hline Aspartate aminotransferase, peak (U/L) & $297 \pm 124$ & $358 \pm 107$ & 0.064 \\
\hline Alanine aminotransferase, peak (U/L) & $296 \pm 108$ & $270 \pm 95$ & 0.416 \\
\hline INR, peak & $1.54 \pm 0.16$ & $1.62 \pm 0.18$ & 0.176 \\
\hline \multicolumn{4}{|l|}{ Biliary complications } \\
\hline Leak & & & 0.693 \\
\hline A & 3 & 2 & \\
\hline B & 1 & 0 & \\
\hline C & 0 & 0 & \\
\hline Stricture & 0 & 0 & - \\
\hline All complications grades according to Clavien-Dindo classification & & & 0.693 \\
\hline l & 3 & 2 & \\
\hline$\|$ & 1 & 1 & \\
\hline III & 2 & 1 & \\
\hline IVN & 0 & 0 & \\
\hline Hospital stay, mean (days) & $8(6-16)$ & $7(5-11)$ & 0.013 \\
\hline
\end{tabular}

Numbers are means ( \pm standard deviation) or medians (range). 
activities after a median follow up period of 33 months (range 8-66).

\section{Biliary outcomes in the recipients}

Table 3 shows that both groups were comparable regarding age, gender, BMI, disease etiology, MELD score, graft weight to recipient weight ratio, and both cold and warm ischemic times. There were no differences in the number of biliary anastomoses between groups. The number of biliary anastomoses was less than the number of actual ducts, as in few occasions ductoplasty was done. Table 4 shows that there was no statistically significant difference in the incidence of biliary complications between groups.

\section{DISCUSSION}

Despite the build-up of experience over years, biliary complications are still considered the Achilis heel of $\operatorname{LDLT}(5,6)$. As this surgery always involves a healthy young donor, an ethical concern arises regarding

Table 3 - Preoperative and operative recipients' characteristics

\begin{tabular}{|c|c|c|c|}
\hline Variable & $\begin{array}{l}\text { Clips group } \\
(\mathrm{n}=29)\end{array}$ & $\begin{array}{l}\text { ROF group } \\
(n=20)\end{array}$ & $P$ value \\
\hline Age & $55(23-63)$ & $55(18-60)$ & 0.166 \\
\hline Gender $(\mathrm{m} / \mathrm{f})$ & $23 / 6(79.3 / 20.7 \%)$ & $13 / 7(65 / 35 \%)$ & 0.265 \\
\hline BMI27 (16-37) & $26(19-35)$ & 0.226 & \\
\hline $\begin{array}{l}\text { Disease etiology } \\
\text { HCV } \\
\text { HBV } \\
\text { Autoimmune } \\
\text { Budd Chiari Syndrome } \\
\text { Cryptogenic }\end{array}$ & $\begin{array}{c}21(72.4 \%) \\
3(10.3 \%) \\
3(10.3 \%) \\
1(3.5 \%) \\
1(3.5 \%)\end{array}$ & $\begin{array}{c}13(65 \%) \\
3(15 \%) \\
4(20 \%) \\
0 \\
0\end{array}$ & 0.653 \\
\hline MELD score & $16(9-20)$ & $17(10-26)$ & 0.101 \\
\hline GRWR (\%) & $1.1(0.8-1.5)$ & $1(0.8-1.5)$ & 0.754 \\
\hline $\begin{array}{l}\text { Cold ischemic time (minutes) } \\
\text { Warm ischemic time (minutes) }\end{array}$ & $\begin{array}{l}30(20-80) \\
35(25-45)\end{array}$ & $\begin{array}{l}35(20-45) \\
35(25-40)\end{array}$ & $\begin{array}{l}0.657 \\
0.156\end{array}$ \\
\hline $\begin{array}{c}\text { Biliary reconstruction } \\
1 \text { anastomosis } \\
2 \text { anastomoses } \\
3 \text { anastomoses }\end{array}$ & $\begin{array}{c}2(1-3) \\
7 \\
13 \\
9\end{array}$ & $\begin{array}{c}2(1-3) \\
7 \\
11 \\
2\end{array}$ & 0.133 \\
\hline
\end{tabular}

Table 4 Recipients' outcomes

\begin{tabular}{|c|c|c|c|}
\hline Variable & $\begin{array}{c}\text { Clips group } \\
(n=29)\end{array}$ & $\begin{array}{c}\text { ROF group } \\
(n=20)\end{array}$ & $P$ value \\
\hline Biliary complications & $10(34.5 \%)$ & $6(30 \%)$ & 0.744 \\
\hline Leak & $9(31 \%)$ & $6(30 \%)$ & 0.941 \\
\hline A & 6 & 4 & \\
\hline$B$ & 3 & 2 & \\
\hline C & 0 & 0 & \\
\hline Stricture & $4(14 \%)$ & $2(10 \%)$ & 0.679 \\
\hline \multicolumn{4}{|l|}{ Management } \\
\hline ERCP & 4 & 2 & \\
\hline PCD & 3 & 2 & \\
\hline \multicolumn{4}{|l|}{ Biliary related complications according } \\
\hline to Clavien-Dindo classification & $10(34.5 \%)$ & $6(30 \%)$ & 0.744 \\
\hline 1 & 6 & 4 & \\
\hline 2 & 3 & 2 & \\
\hline 3 & 4 & 2 & \\
\hline
\end{tabular}

ERCP; endoscopic retrograde cholangiopancreatography, PCD; percutaneous drainage. 
his/her safety versus the benefit of the recipient. That is why dividing the hilar plate during donor surgery is one of the most stressing steps in this surgery. A line of division that is too close to the donor's junction between common bile duct and left bile duct may lead to biliary stricture in the donor and a too far line may lead to multiple smaller bile ducts on the graft side with subsequent increase in the number and difficulty of biliary anastomoses in the recipient and this had been identified as a risk factor for biliary leak in the recipient (7). Additionally, in order to clearly identify the site of bile duct transection, excessive dissection may lead to biliary ischemia in the graft bile duct(s) which adds a risk factor for leak and subsequent stricture in the recipient (7).

In order to decrease the above-mentioned risks, many innovations were devised to increase accuracy of bile duct transection (2). Metal clips were classically used as radiopaque markers to identify the exact site of transection under IOC guidance. The use of metal clips as markers was associated with many problems. First, as they were applied to the edge of hilar plate, they were not overlying the enclosed bile ducts and their relation with the bile duct was sometimes difficult to interpret in IOC. That was why many IOC's were usually required with snip by snip cutting of hilar plate. Second, they were frequently detached or twisted after their application requiring their re-application and possibly repetition of IOC multiple times. Moreover, metal clips were sometimes not clearly visible on the IOC's, or they mingle with other clips already in the field. All these problems with metal clips not only increase the time, number of IOC and difficulty of the procedure but also reduce the accuracy of determining the proper line of transection and leads to some hesitation that inadvertently pushes the surgeon to favor donor safety and shifts the transection line a bit towards the graft side leading to more number of stumps. Other innovative techniques were devised as the use of real-time indocyanine green fluorescence cholangiographic guidance in either open (8) or laparoscopic donor hepatectomy (9) or the use of ultrasonographic guidance for the same purpose (10). In addition, some authors reported that they entirely replaced IOC with MRC for the sake of noninvasiveness (11).

We have recently shifted to the use of a radioopaque filament as a marker under IOC guidance, with their fixation with fine stitches at two points overlying the hilar plate. With this simple and minor modification, we could have better interpretation of the anatomy as these long thin filaments are crossing perpendicular to bile ducts in $\mathrm{IOC}$ with decreasing the number of ducts on the graft side without violating donor safety. Additionally, as hilar plate is now divided in one session, usually only one $I O C$ is required during this step. Furthermore, there is no fear from detachment or twisting of the filaments compared to the previously used clips.

A similar technique was described by Takatsuki et al in 2006 (12) and its modification in 2011 (13) in which they completely encircled the hilar plate containing the bile duct(s) to be transected by a radiopaque marker filament. They interestingly reported that their modification significantly reduced the number of multiple bile ducts in the graft. Our described technique is a modification of Takatsuki's, where we simply stitch the filament(s) on the anterior surface of the right hilar plate instead of encircling it for the fear of the risk mentioned by Takatsuki et al of the possibility of injury to the hilar plate during the encirclement.

After applying this simple modification, the number of bile ducts encountered on the graft side and the number of IOC's performed were significantly reduced compared to the previous technique. For the purpose of this study we defined a statistic that is "imprecisetransection" which is counted if the number of bile ducts openings after transection turned out to be more than the estimated number of ducts in IOC. This number was less with the use of ROF.

The number of anastomoses performed and the number of biliary complications in the donors and recipients were not statistically significant, perhaps due to the small number of patients and low power of the present study, or due to the low overall number of complications in the this series. Similar to our findings; Arikan et al (14) and Kollmann et al (15) had reported that multiplicity of graft bile ducts was not associated with an increase in biliary complications. Both had attributed this to the recent increase in experience and improvement of surgical techniques which led to the minimization of the effect of multiple bile ducts on outcome. Interestingly; both authors had showed that this finding is a recent improvement by comparing their latest results to their own earlier results $(16,17)$. Finally, the shorter hospital stay in the ROF group in the current study can be merely attributed to the gradual implementation of expeditious recovery program in the later era.

One disadvantage of the current technique was the difficulty in fixing the filaments with stitches to the hilar plate in comparison with the easy application of clips. However, the mitigation it provides to the subsequent steps and the precision of hilar plate division it offers outweigh this disadvantage and justify its use. 
In conclusion, marking biliary division by ROF is a simple and minor modification, but has the advantage of decreasing the difficulty of surgery and reduces exposure of donor and operating team to radiation.

\section{Ethics approval and consent to participate}

Ethics approval was obtained by Faculty of Medicine Ethical Committee, Assiut University, Egypt (ref. IRB_04_07022020). Signed committee approval is kept by the researchers.

\section{Consent for publication}

All patients included in this research gave written informed consent to publish the data contained within this study.

\section{Availability of data and material}

The datasets used and/or analyzed during the current study are available from the corresponding author and can be submitted if requested.

\section{Conflicts of interests}

The authors declare that there is no conflict of interest regarding the publication of this paper.

\section{Funding}

The authors received no specific funding for this work.

\section{REFERENCES}

1. Rao HB, Prakash A, Sudhindran S, Venu RP. Biliary strictures complicating living donor liver transplantation: Problems, novel insights and solutions. World J Gastroenterol. 2018;24(19):2061-72.

2. Marubashi S, Dono K, Nagano H, Kobayashi S, Takeda Y, Umeshita
$\mathrm{K}$, et al. Biliary reconstruction in living donor liver transplantation: technical invention and risk factor analysis for anastomotic stricture. Transplantation 2009:88:1123-30.

3. Dindo D, Demartines N, Clavien PA. Classification of surgical complications: a new proposal with evaluation in a cohort of 6336 patients and results of a survey. Ann Surg. 2004;240(2):205-13.

4. Koch M, Garden OJ, Padbury R, Rahbari NN, Adam R, Capussotti L, et al. Bile leakage after hepatobiliary and pancreatic surgery: a definition and grading of severity by the International Study Group of Liver Surgery. Surgery. 2011;149(5):680-8.

5. Simoes P, Kesar V, Ahmad J. Spectrum of biliary complications following live donor liver transplantation. World J Hepatol. 2015; 7(14):1856-65.

6. Koneru B, Sterling MJ, Bahramipour PF. Bile duct strictures after liver transplantation: a changing landscape of the Achilles' heel. Liver Transpl 2006;12:702-4.

7. Wang SF, Huang ZY, Chen XP. Biliary complications after living donor liver transplantation. Liver Transpl. 2011:17:1127-36.

8. Mizuno S, Isaji S. Indocyanine green (ICG) fluorescence imagingguided cholangiography for donor hepatectomy in donor liver transplantation. Am J Transplant 2010;10:2725-6.

9. Lee JM, Lee KW, Hong K, Han ES, Hong SK, Yi NJ, et al. Various techniques for bile duct division in pure laparoscopic donor hepatectomy. Laparosc Surg 2020;4:24.

10. Rhu J, Choi GS, Kim JM, Kwon CHD, Joh JW. Intraoperative Ultrasonography as a Guidance for Dividing Bile Duct During Laparoscopic Living Donor Hepatectomy. Ann Transplant. 2019; 24:115-22.

11. Kim SH, Lee EC, Lee SD, Park SJ. Ligation and cut as a method for bile duct division in living donor right hepatectomy. Liver Transpl. 2017:23:448-56.

12. Takatsuki M, Eguchi S, Tokai H, Hidaka M, Soyama A, Tajima Y, et al. A secured technique for bile duct division during living donor right hepatectomy. Liver Transpl. 2006;12:1435-6.

13. Takatsuki M, Eguchi S, Yamanouchi K, Hidaka M, Soyama A, Kanematsu T. Technical refinements of bile duct division in living donor liver surgery. J Hepatobiliary Pancreat Sci. 2011;18(2):170-5.

14. Arikan T, Emek E, Bozkurt B, Mammadov E, Ceyhan O, Sahin T, et al. Does multiple bile duct anastomosis in living donor liver transplantation affect the postoperative biliary complications? Transplant Proc. 2019;51(7):2473-7.

15. Kollmann D, Goldaracena N, Sapisochin G, Linares I, Selzner N, Hansen $\mathrm{BE}$, et al. Living donor liver transplantation using selected grafts with 2 bile ducts compared with 1 bile duct does not impact patient outcome. Liver Transpl. 2018;24(11):1512-22.

16. Yaprak O, Dayangac M, Akyildiz M, Demirbas T, Guler N, Bulutcu F, et al. Biliary complications after right lobe living donor liver transplantation: a single-centre experience. HPB (Oxford). 2012; 14(1):49-53.

17. Kim PT, Marquez M, Jung J, Cavallucci D, Renner EL, Cattral M, et al. Long-term follow-up of biliary complications after adult right-lobe living donor liver transplantation. Clin Transplant. 2015;29(5): $465-74$ 